\title{
THE REAL GEOMETRY OF THE EGYPTIAN PYRAMIDS
}

\begin{abstract}
Sofias Sotirios*
*Corresponding Author: Sofias Sotirios, Geodesy (National Technical University of Athens, Faculty of Surveying Engineering), Gis expert (ArcGis ESRI), author of the historical books Orpheus \& Argonauts, Atlantis of Plato, Centauri, Athens, Greece.E-mail:sotosofias@yahoo.gr
\end{abstract}

\section{ABSTRACT \\ An analytical Geometrical calculation of the Pyramids of Giza \\ Keywords: Pyramids, Ancient Egypt, Herodotus, Orion constellation, Giza, Khufu, Khafre, Menkaure}

\section{INTRODUCTION}

The main goal of this research is to identify the real geometrical relation of the Pyramids of Giza using the ultimate applications such as AutoCAD and Google Earth base maps.

\section{THE PYRAMIDS OF GIZA}

In the recent years I have been studying the Pyramids of Giza, especially how they were built, and whether they were tombs of the Pharaohs or something else. But mainly as a surveyor I wanted to know the secrets of their construction. I assume that some ancient engineers probably drew the pyramids on a piece of paper and my ancient fellow surveyors undertook to carry out the ambitious plans of the Pharaohs.

Till recently, it was impossible to visit the area of the pyramids and set up a geodetic station with built-in GPS points, measure the pyramids (either in an independent coordinates system or in a global one) and draw them on a piece of paper. But today, having in my hands the "super weapons" Google Earth, AutoCAD and the astronomical programs Redshift \& Celestron, I will try for the first time to unravel the secrets of the Pyramids, in terms of their geometry.

In the 1980s, two researchers, Hancock and Bauval, published their research with the correlation of the Pyramids with the 3 stars of the socalled Orion Belt, the stars Mintaka, Alnilam and Alnitak. But the information they presented, was general and vague. They relied on measurements made on paper with a ruler and protractor, while I made all the exact calculations through AutoCAD. Do the three Pyramids of Giza have any conjunction with the 3 stars of the Orion belt as claimed by the 2 
researchers? At first glance yes. But it remains to be seen, using current technology, how similar and different they look.

From the astronomical program Celestron the Sky using the print screen function, I downloaded in jpg the zone of Orion with the 3 stars.

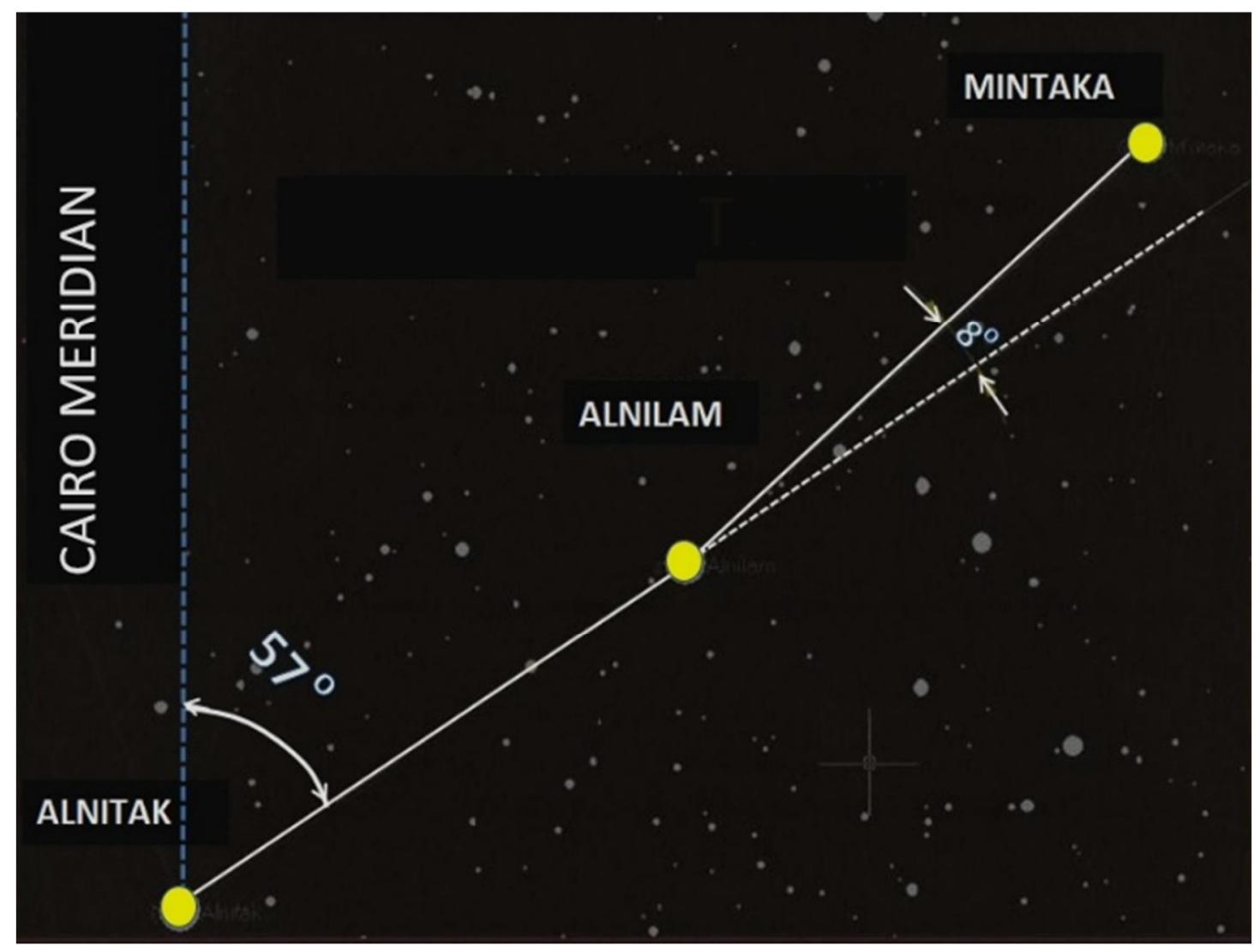

Figure 1. The Orion Belt with the three stars almost aligned, as sheen from the Cairo's Meridian. Mintaka is located $8^{\circ}$ northern of the linear alignment of the 2 stars.

The azimuth of the 2 star is $57^{\circ}$

I chose the moment of the constellation located at the meridian of Sais (i.e. present Cairo) because only then the constellation has the right place in the sky. I put it in AutoCAD and calculated the complementary angle formed by the 3 stars in the plane, with the central star Alnilam at the vertex and I found the angle $\varphi=8^{\circ}$. The Cairo's meridian forms an inclination angle with the first 2 stars of $57^{\circ}$. To avoid any accidental error, I did the same thing, by downloading the constellation Orion through Google Earth, using the "sky" option. In both cases, the programs confirm that the external angle is $8^{\circ}$. It makes no sense to calculate the angle more accurately (i.e. by 1 or 2 decimal places) since the stars are so small and so close to each other that to the naked eye it simply seems out of alignment. The Pyramids of Giza are the oldest surviving monument of the Seven Wonders of the Ancient World. Their construction, according to modern Egyptology, dates to $2580 \mathrm{BC}$ and is located in the Necropolis of Giza. The largest and most famous is the pyramid of Khufu while the other two are smaller and are 
located a few meters away from the pyramid of Khufu (i.e. Cheops in ancient Greek).

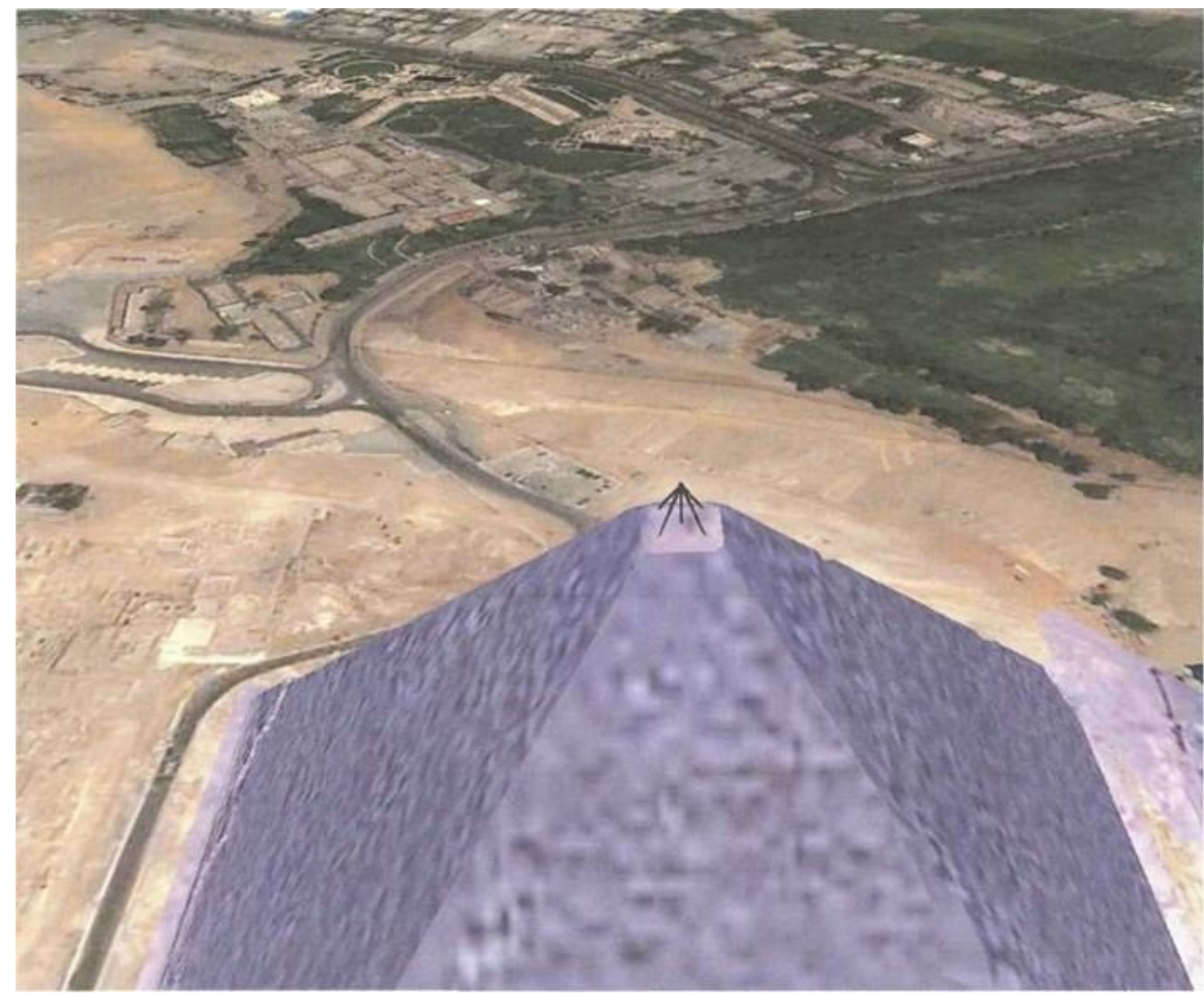

Figure 2. The Pyramid of Khufu is also known as the Great Pyramid. Amazing 3D photo from Google Earth. Something like a tripod seems to be installed on top of it. Theoretically, it is the tomb of Khufu, but this, from the analysis of the writings of Herodotus, is categorically excluded.

Any differences in lengths or heights on different sites and in Google Earth do not affect my measurements in any way. I'm not looking to find accuracy of an inch, not even a meter. But to find how the pyramids were designed on the ground, the measurements I have at my disposal are more than enough. On the other hand, due to erosion, there is an alteration from the original dimensions and that is why infinite dimensions are circulating on the internet. I will select the ones that result from Google Earth with whatever accuracy corresponds to them. So according to the $3 \mathrm{~d}$ model of Google Earth (i.e., by placing the cursor at the top of the pyramid), the altitude of $213 \mathrm{~m}$ appears in the line of geographical coordinates. That is, the pyramid has an absolute altitude at the top of $h=213 \mathrm{~m}$. (i.e. from the sea surface). At the base of the pyramid there is something like a quay around the perimeter, which has an absolute altitude of $\mathrm{h}=66 \mathrm{~m}$. So, the net height of the pyramid is $h(213-66)=147$ meters. According to 
Wikipedia, its height is $146.60 \mathrm{~m}$, and the perfect square base has a side of $230.35 \mathrm{~m}$. Measuring with the Measure Tool of Google Earth, the quay is 240 meters long and 5 meters wide, so the pyramid has even today side 230 meters. Initially the Great Pyramid was covered with overlapping stones which created a smooth and flat surface. What we see today is the. structure below. Today, we can see some of these overlapping stones scattered around the base of the pyramid. There are three well-known chambers in the Great Pyramid. The one that is lower, is dug in the rocky substratum below the pyramid and is unfinished. The mass of the pyramid is estimated at 5.9 million tons. Its volume is about 2,500,000 cubic meters. Based on these calculations, building the pyramid within 20 years would require the laying of 800 tons of stone every day. Similarly, as the pyramid is estimated to consist of approximately 2.3 million monoliths, for 20 years it is required to move 12 monoliths per hour, every day, 24 hours a day. The limestone of Tura, which was used for the outer covering, has been mined from the opposite bank of the river. The largest granite monoliths in the pyramid have been found in the "King" chamber, weighing 25 to 80 tons, and have been transported from Aswan, which is 800 kilometers away. It is estimated that 5.5 million tons of limestone, 8,000 tons of granite (brought from Aswan), and 500,000 tons of plaster were used to build the pyramid.

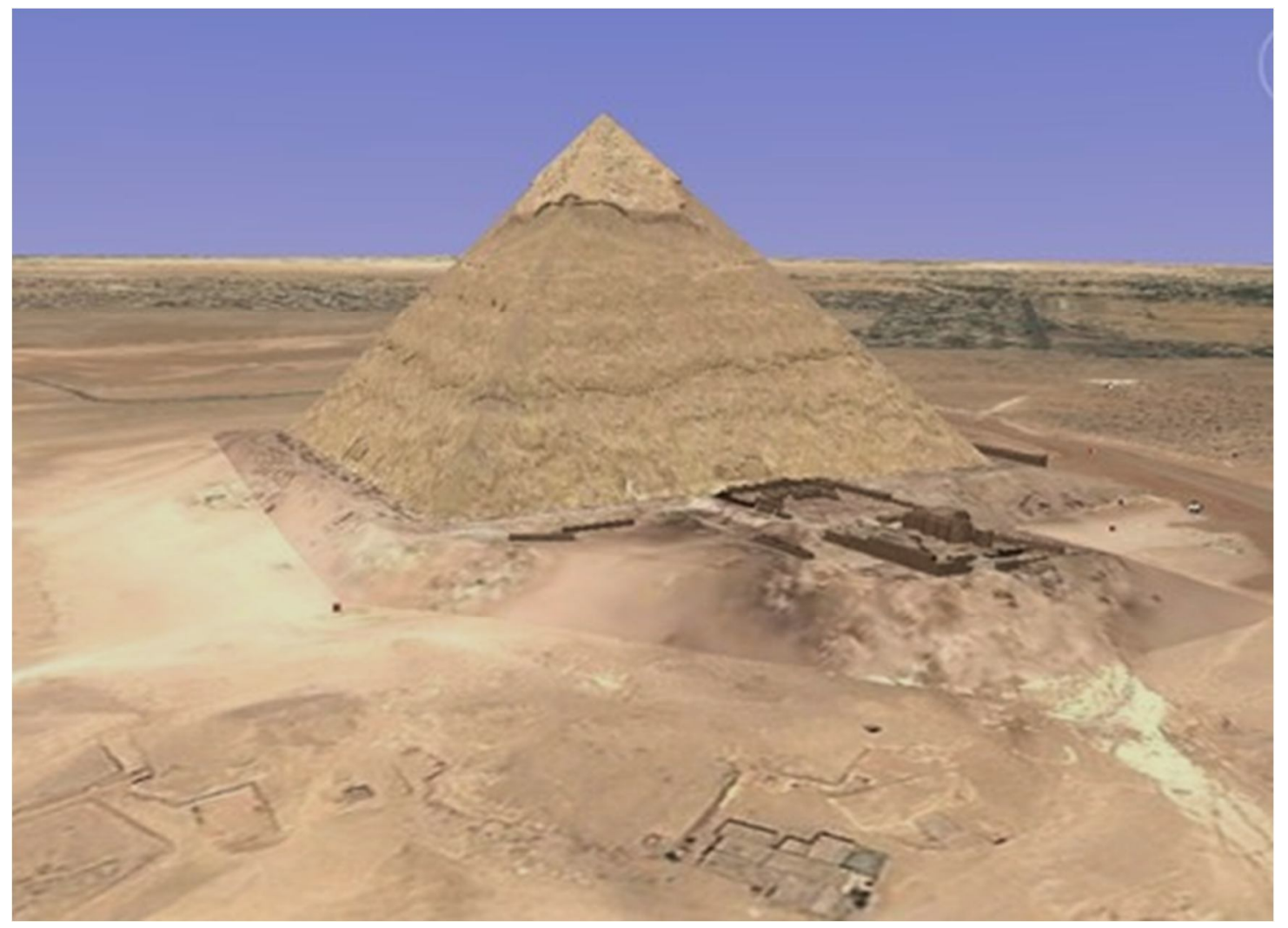

Figure 3. The Pyramid of Khafre, through a wonderful 3D screenshot of Google Earth. It is the second largest of the Pyramids of Giza and theoretically the tomb of Pharaoh, of the Fourth Egyptian Dynasty, of Khafre (Khefren). But even this was not Pharaoh's tomb. The Pharaohs, as Herodotus proves, were buried elsewhere. 
According to the $3 \mathrm{~d}$ model of Google Earth, by placing the cursor at the top of the pyramid, the altitude of $211 \mathrm{~m}$ appears in the line of geographical coordinates. That is, the pyramid has an absolute altitude at the top of $h=$ 211 meters (i.e. from the sea surface). In conclusion, the 2 large pyramids have at their top almost the same altitude, about 212 meters!!! At the base of the pyramid there is something like a hill that has an absolute height of $\mathrm{h}=74$ meters. So, the net height of the pyramid is $\mathrm{h}=211-74=137$ meters. According to Wikipedia, its height is $136.40 \mathrm{~m}$ and the square base has a side of $215.5 \mathrm{~m}$. Measuring with the Measure Tool of Google Earth, its length is 208 meters. Referring to the ancient text, Herodotus mentions that the pyramid of Khafre is 40 feet lower, (i.e. 12 meters) than that of Khufu. The google measurements, as I recorded them before, give: Altitude of Khufu minus Altitude of Khafre $=147-137=10$ meters. That is about 40 feet. Exactly as Herodotus mentions. Due to the slope of the plateau on which the pyramid is built, the northwest corner was cut 10 meters ( 33 feet) from the rocky subsoil, and the southeast corner is elevated. The pyramid is built in horizontal layers. The stones used at the base are very large, but as we go up, they become smaller, only $50 \mathrm{~cm}$ (20 inches) wide at the top. The layers are rough and irregular up to the middle, but a narrow strip with a symmetrical build is evident in the middle. There are external overlapping stones in the last third, but the pyramid and part of the top are missing. The lower layers of the coating are made of pink granite, while the rest of the pyramid is made of Toura limestone. A careful examination reveals that the overlapping stones at the corners of the pyramid are not completely straight but deviate a few millimeters. In one case this is the result of seismic activity, while in another it is claimed that the slope of the pieces was given before they were placed, due to limited space as the pyramid went up. The Pyramid of Menkaure, the smallest one of the three Pyramids of Giza. It was built - always in theory - as the tomb of Pharaoh of the Fourth Egyptian Dynasty, Menkaure. 


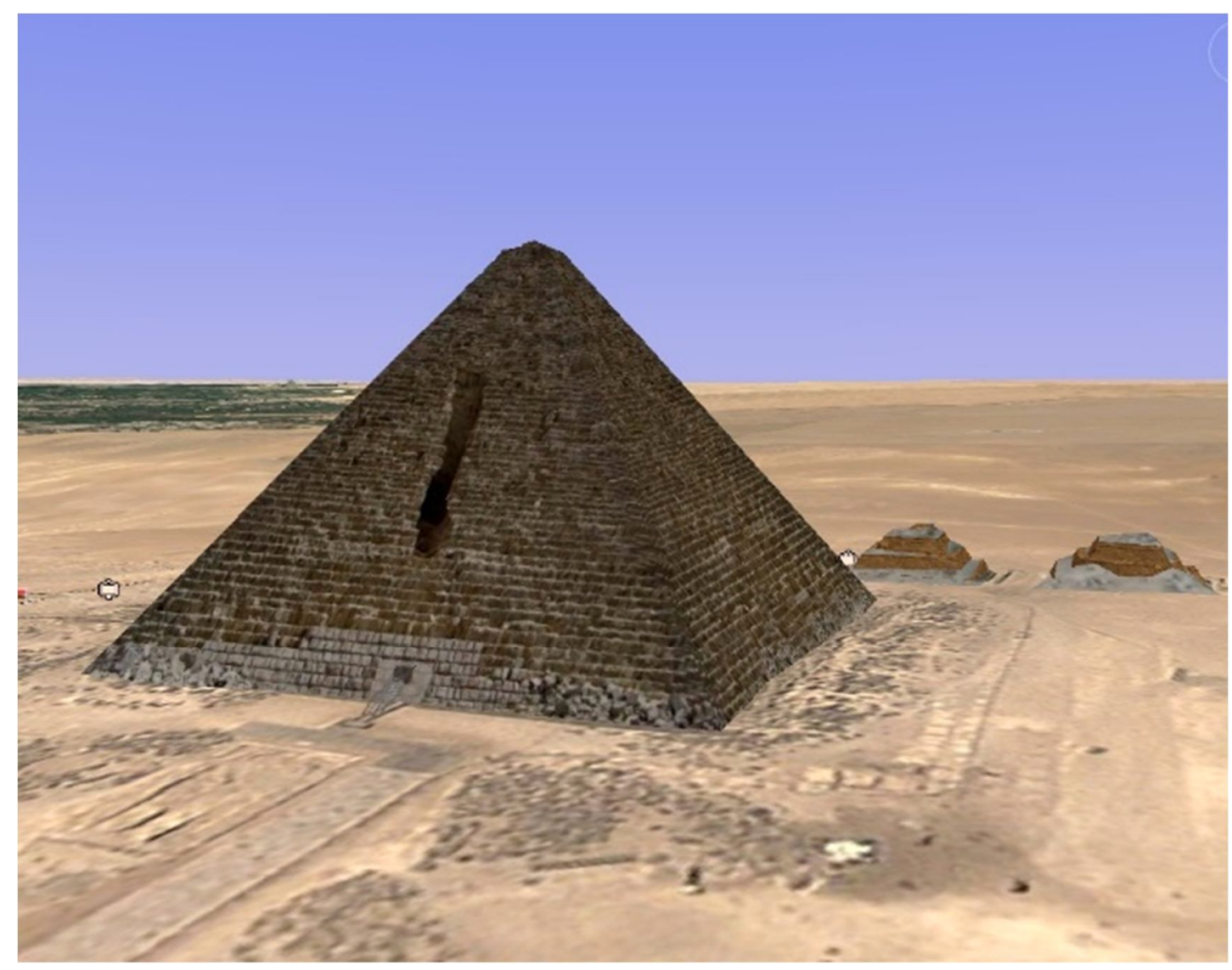

Figure 4.The Pyramid of Menkaure, a wonderful 3D screenshot of Google Earth.

The Pyramid of Menkaure (source Wikipedia) had an initial height of 65.5 meters (215 feet) and was the smallest of the three great Pyramids of the Necropolis of Giza. It is now 61 meters high (204 feet) and has a base of 95 meters. Also, this pyramid is made of limestone and granite. The first 16 layers on the outside are made of granite, and the top is made of limestone from Toura. Part of the granite is raw. Similar parts that have remained unfinished help archaeologists to understand the methods by which pyramids and temples were built. South of the pyramid are three smaller "satellite" pyramids, none of which had been completed. The largest of these was made of granite. The construction of the other two remained incomplete and never went beyond the inner core of the pyramid. Using the $3 \mathrm{~d}$ model of Google Earth (i.e. placing the cursor at the top of the pyramid), the altitude of $134 \mathrm{~m}$ is displayed in the line of geographical coordinates. That is, the pyramid has an absolute altitude at the top of $\mathrm{h}=$ $134 \mathrm{~m}$. (i.e. from the sea surface). At the base of the pyramid there is something like a hill that has an absolute height of $h=70 \mathrm{~m}$. So, the net height of the pyramid is $\mathrm{H}=134-71=63$ meters. Side length in Google Earth, is about $95 \mathrm{~m}$. (I will use this figure in my measurements). At this scale, the difference of a few meters does not affect the geometry. The layout on the site will have some metric errors. So, when the bases of the 3 pyramids were implemented on the ground, they would have deviations 
from the original plan. In fact, when the construction of these megalithic monuments began, it is logical that the workers could not place the stones to the nearest centimeter, as the engineers of the project might have wanted. So, putting the 2 photos one below the other, I kept the same relative scale so I could draw conclusions. I concluded that the 3 pyramids with the 3 stars of Orion look to have the same scheme, but they do not much since the geometric relation that connects them is different, as I will prove below.

The Orion belt scale is small in relation to the pyramids. However, with the help of AutoCAD, the two schemes acquired the same relative scale, so that they can draw direct conclusions. At first glance, the two stars Alnilam \& Alnitak correspond to Khufu \& Khafre, but Mintaka is not projected on Menkaure. That is, the distance Alnilam-Mintaka is not proportional to the distance of Khafre-Menkaure. There is an error. Also, to match the two projections, I had to turn the photo of the stars $12^{\circ}$ counterclockwise so that instead of $57^{\circ}$ the angle becomes $45^{\circ}$. That is, only in the $45^{\circ}$ position can the 2 photos be partially matched. This photo is an enlargement of the lower half of the previous one. The projections of the 3 stars on the ground are yellow. The 2 stars Alnilam \& Alnitak are projected exactly on the 2 big Pyramids of Khufu and Khafre respectively. However, the small pyramid of Menkaure, which corresponds to the projection of the star Mintaka (the far-right yellow line) does not pass exactly at the top of the pyramid. In conclusion these are the three major geometric errors which disprove the Hancock-Bauval theory:

1. The azimuth of the stars of the constellation is $57^{\circ}$ while that of the pyramids is $45^{\circ}$. (Identification: The azimuth in the ancient times was measured from south to west and not from north to east as usually happens today)

2. Mintaka is more far to the central star than the pyramid of Menkaure to that of Khafre.

3. The central angle of the 3 stars (i.e. with Alnilam as vertex) is $8^{\circ}$ while the central angle of the pyramid with Khafre as vertex, is $12^{\circ}$.

After this detailed geometric analysis, I concluded that the 3 pyramids may look like the 3 stars of the Orion belt, but Menkaure's error leads me to the conclusion that the Hancock-Bauval theory is incorrect. 


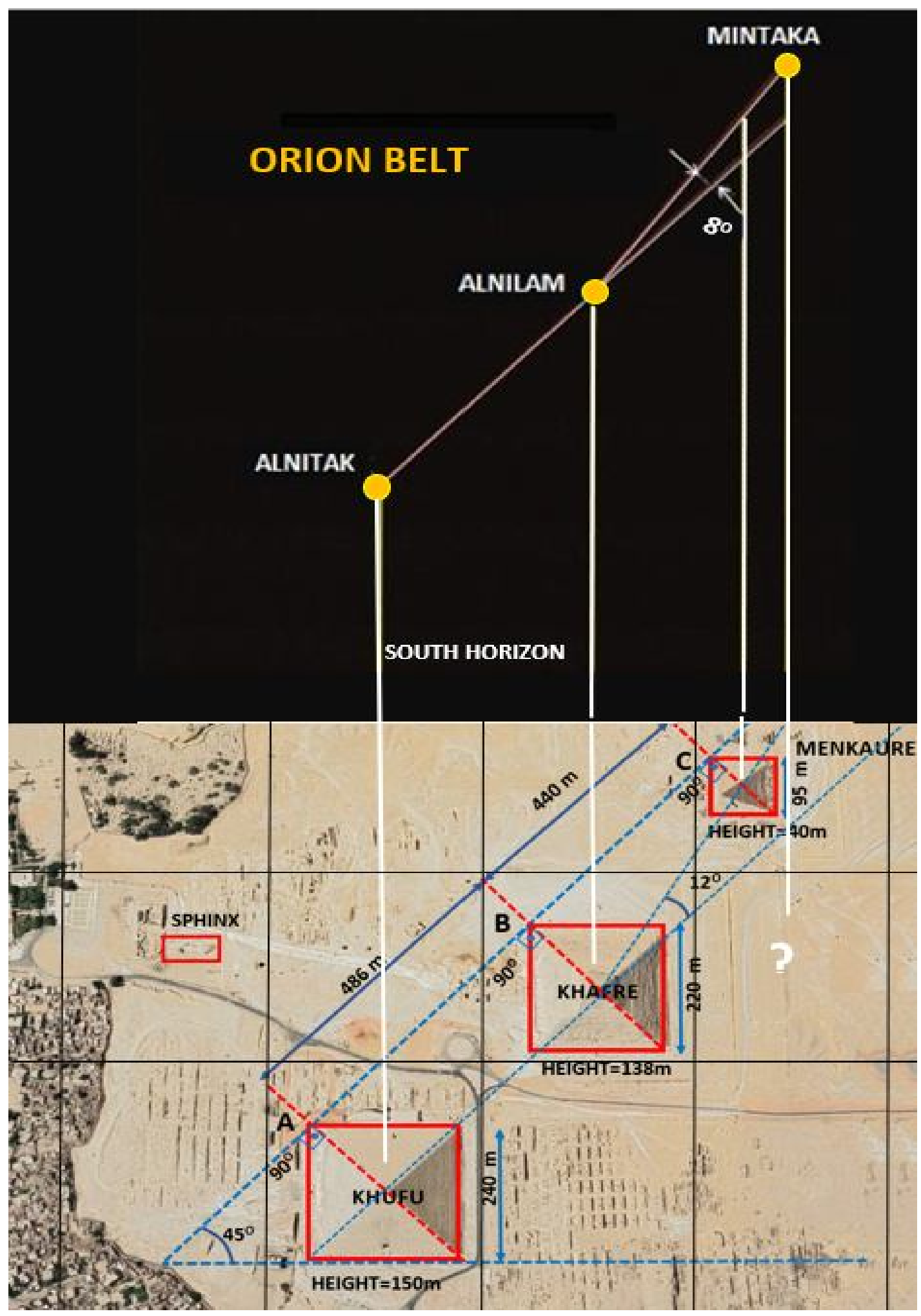

Figure 5. The combined photo from AutoCAD with the constellation of Orion and the pyramids in the same horizontal plane. This is how the pyramids are projected on the ground, for someone who sees them to the South. Mintaka is out of the projection (i.e white question mark). The diagonal of the 3 pyramids (i.e. the red dotted line) is vertical to this line and as a result all the sides of the pyramids are parallel to the global geographical grid (i.e. on the pyramid's photo, the black horizontal and vertical lines represent the longitude \& the latitude). 


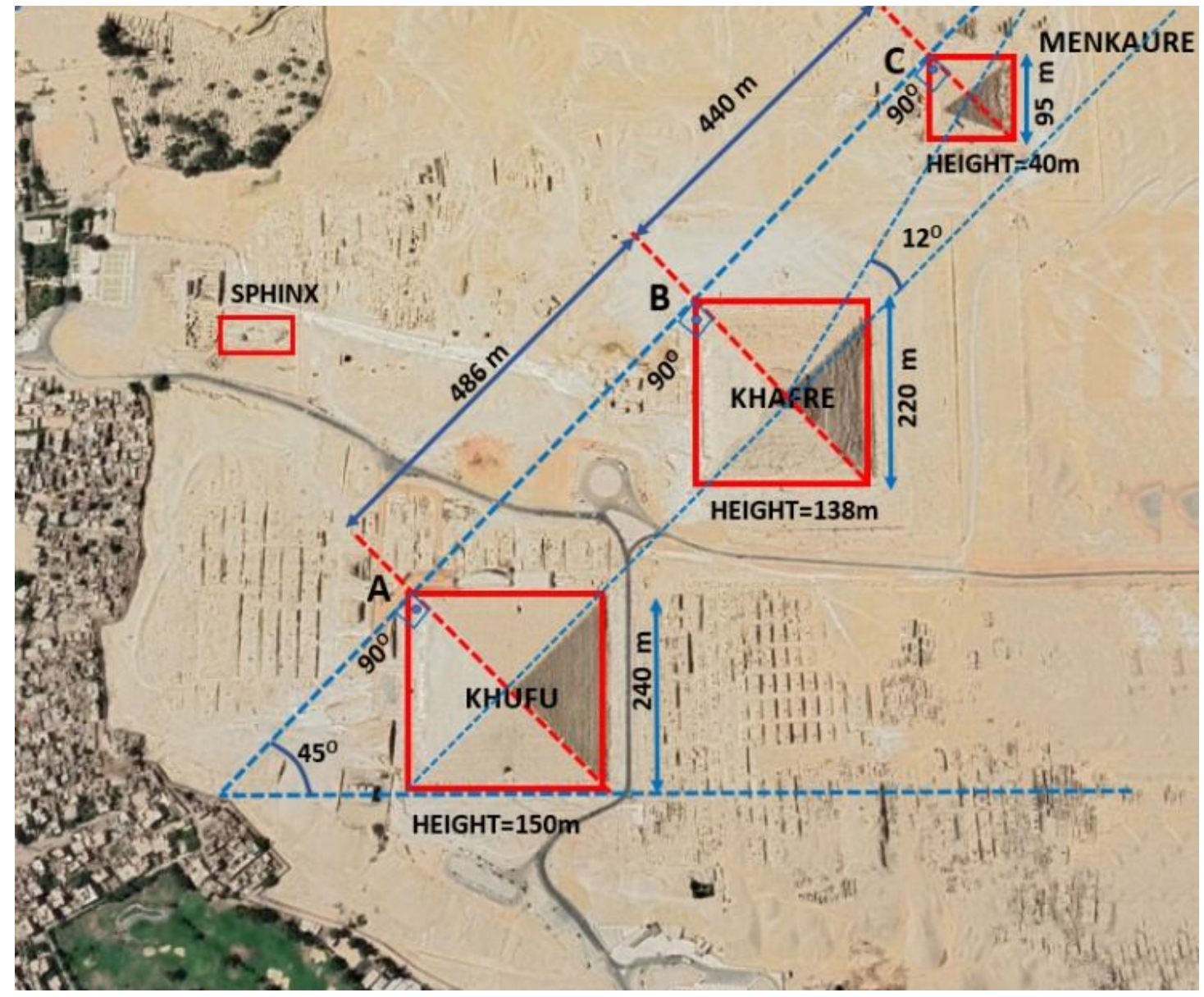

Figure 6. The geometrical relation between the three pyramids is finally revealed due to the amazing Google Earth: The alignment of the 3 south east vertices A,B,C on a line with inclination of $45^{\circ}$. This is the way the 3 pyramids were constructed and not according to the 3 stars of the Orion Belt as Hancock and Bauval claims.

\section{CONCLUSIONS}

Analyzing the above photo, I pointed out some amazing features for the layout of the pyramids.

- The white horizontal and vertical white lines represent the parallel and meridian of the area. What do we observe? That the sides of the pyramids are parallel to these lines. So, it turns out that the pyramids are absolutely oriented to the global geographical grid!!!

- The 3 pyramids are aligned. In fact, this line is oriented almost $45^{\circ}$ in a NE-SW direction!

- The diagonals of each pyramid are vertical on this line!!! So, it is explained how the pyramids were built, how they were implemented on the ground. In other words, the ancient surveyors drew a line on the ground with an orientation of $45^{\circ}$ to the geographical north pole or equivalently $135^{\circ}$ to the south pole. Then at a random point they brought a vertical with 
a length of 340 meters. This was the diagonal of the square pyramid side 240 meters. Thus began the pyramid of Khufu. Then, at a distance of 486 meters, they brought new perpendicular to the alignment with a length of 310 meters. This was the diagonal of the square pyramid of Khafre, side 220 meters!!! The surveyors therefore placed the 3rd pyramid at 440 meters and always in contact with the straight orientation. They brought the vertical line with a length of 134 meters and thus the base of the 3rd pyramid of Menkaure was created, with a side of 95 meters.

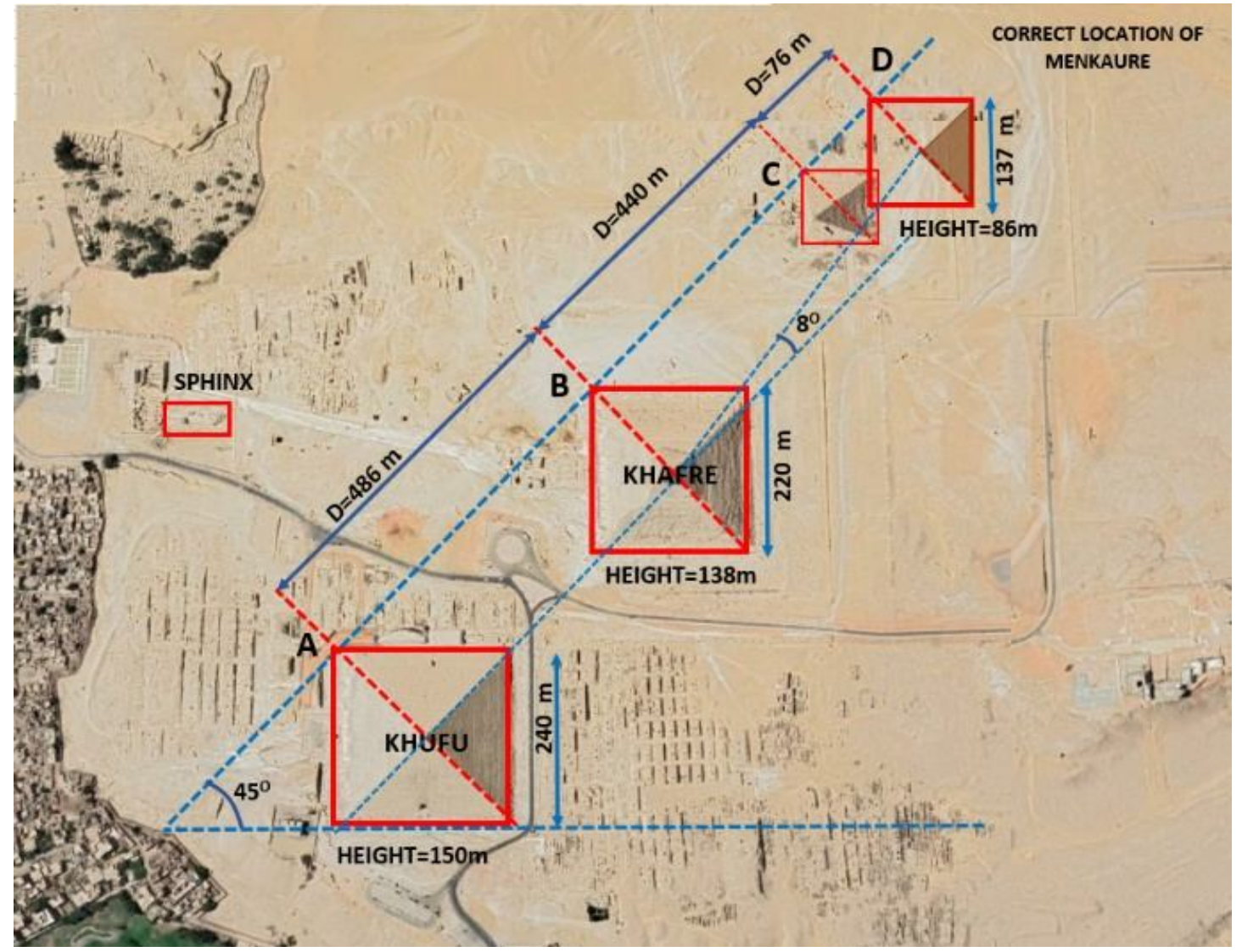

Figure 7. The correct location of Menkaure's pyramid should be at point $D$ and not $C$ as it is today. According to the proportion of the 3 stars of the Orion belt, the right figures are: Deviation angle $8^{\circ}$ and distance from Khafre's pyramid $440+76=516 \mathrm{~m}$.

So, if the ancient geodesic astronomers really wanted to depict the stars of Orion on the ground-given that they are a marvel of engineering-I think they could not make a mistake at the corner of the Pyramids $4^{\circ}$ or $76 \mathrm{~m}$ away. It seems that the 3 pyramids do not follow the order of Orion, but the geometric relationship where the 3 vertices are in the same line. As a result, the sides of each pyramid are perfectly oriented to the 4 points of the horizon. To apply the Orion constellation exactly to the pyramids, I used AutoCAD. The point -where the $8^{\circ}$ angle intersects with the projection at the level of the Mintaka star (penultimate right yellow line) - 
was the center of the 3 rd pyramid. From that point, I brought perpendicular line to the blue orientation one. I measured it 93.5 meters, and found the diagonal of the square, equal to 187 meters. Then I constructed a square with a diagonal of 187 meters, the side of which is shown by the program to be 137 meters. In this way, the Pyramid of Menkaure forms an angle of $8^{\circ}$ but also touches the orientation line. Measuring the displacement distance of the new position of the pyramid, in relation to the existing one, I found it 76 meters. So, the right side of the Pyramid of Menkaure should have been 137 meters and the distance $D=440+76=516$ meters away from the Pyramid of Khafre. This is the "mistake" of Menkaure that I restored in the computer. I don't know if the ancient builders of the pyramids had the constellation of Orion in mind as many researchers claim. Its very easy to connect them since the stars of the Orion belt are three, and the pyramids of Giza are also three.

But someone who "copied" the constellation and applied it to the earth has made significant mistakes that are not justified given his knowledge and technological superiority. This photo is the correct projection on the ground of the 3 stars of the so-called Orion Zone and refutes the HancockBauval theory.

\section{REFERENCES}

[1] Pyramids of Giza by Wikipedia

[2] Herodotus Histories (book Euterpe)

[3] Google Earth

[4] Hancock \& Bauval documentary

Citation: Sofias Sotirios. "The Real Geometry of the Egyptian Pyramids"

Copyright: (c) 2021 Sofias Sotirios. This is an open-access article distributed under the terms of the Creative Commons Attribution License, which permits unrestricted use, distribution, and reproduction in anymedium, provided the original author and source are credited. 